\title{
Effect of incremental static damage on modal frequencies of reinforced concrete beams
}

\author{
Muhammad Usman Hanif ${ }^{1, *}$, Zainah Ibrahim ${ }^{1, *}$, Huan Xin Lim ${ }^{1}$, You Xian \\ Hang $^{1}$
}

${ }^{1}$ Department of Civil Engineering, Faculty of Engineering

University of Malaya, 50603 Kuala Lumpur, Malaysia.

Received 01 January 2018; accepted 15 April 2018, available online 07 May 2018

\begin{abstract}
The modelling and the failure mechanisms of RC structures is a complex phenomenon because the constituent materials' strengths are combined to overcome their weaknesses. Therefore, the failure mechanisms have not been understood completely. Modelling concrete beams using plasticity approaches has gained a lot of attention because of its versatility. This research incorporates the plasticity model with continuum damage model to evaluate the modal frequency deterioration of the reinforced beams. These beams were incrementally damaged in flexure using finite element modelling. It was observed that the model represents the damage mechanism of RC beams quite reasonably. The dynamic response of the beams is also in line with the experimental results. Based on the dynamic response, it was observed that the modal frequencies are sensitive to damage at initial stages and there is not significant reduction in the natural frequencies at complete damage.
\end{abstract}

Keywords: Constitutive relations, $\mathrm{RC}$ beams, concrete damaged plasticity, modal analysis

\section{Introduction}

Reinforced concrete modeling has been a major issue for more than half a century. It is the most used man-made construction material in the world and the existing serviceable infrastructure construction goes back to centuries [1]. Concrete structures, undoubtedly are the most serviceable, stable, economical and durable. But these structures are constantly exposed to environmental hazards (weather conditions, wind loads, seismic activity, abruptly varying traffic loads) and may degrade before their intended design life.

With the advent of structural health monitoring in civil engineering structures, various techniques have been adopted from mechanical and aerospace health monitoring systems. Implementing these damage identification techniques on civil infrastructure without interrupting the serviceability has been a great challenge. With the advent of time, various new damage detection techniques have been adopted which include visual inspection techniques, vibration inspection, acoustic emissions, ultrasonic techniques, magnetic particle, radiography, eddy current measurements along with various enhancements in the sensing technology and the automation [2]-[8]. Among these techniques, the most popular technique is using the vibrations [9]-[11].

The vibration damage detection techniques have been applied in damage detection of bridges. These techniques were found to be reasonably effective in condition assessment [12]-[16]. But it was later found that these techniques are not adequately sensitive to damage detection and non-linearities are formed in structures after the damage starts [17], [18].

Various techniques have been used, various methods have been incorporated to identify the damage in reinforced concrete beams. The recently applied technique makes use of introducing the incremental static damage and then utilizing the vibrations to identify the current condition of the structure [19]. This gives the global response of the structure at the known extent of the damage. This behavior of the structure can be used to identify the modal response of the structure. The failure mechanisms have been incorporated using fictitious crack model [20]. The research development was further confirmed by the authors using plastic-damage model [21]. This type of modal analysis of structures at known damage levels has not been given much importance.

The purpose of this study was to investigate the modal response of the reinforced concrete beams at the incremental static damage. The dynamic response of the beam was analyzed after each increment in static loading. Furthermore, the crack formation in the damage regime was related to the reduction in modal frequencies. First four flexural modes were investigated against the incremental static damage. The efficacy of the model was further confirmed by the experimental investigation on the reinforced concrete beam.

\section{Concrete beam modelling}

Concrete damaged plasticity model was used to model reinforced concrete beam. The continuum damage model 
[22] was coupled with plasticity as a damage indicator in tension and compression. The uniaxial stress-strain behavior in compression was adopted using Carreira's model [23]. For uniaxial tensile behavior, the fictitious crack model was incorporated [24]. The next subsections will briefly state the material properties, the geometric properties of the test specimen and the analysis procedures involved.

\subsection{Material modelling}

A concrete mix design similar to $\mathrm{C} 40$ grade concrete was used and the concrete average compressive cylinder strength of 28 days was $36.08 \mathrm{MPa}$ with corresponding split cylinder strength of $3.90 \mathrm{MPa}$. The mechanical properties obtained from material testing are shown in Table 1. These parameters were the input parameters for modeling of constitutive relations and later the plastic damage model. As the hardening and softening behavior of concrete can be explained by a reasonably simple relation in Carreira and Chu's model [23], this simple relation was used to model the uniaxial compressive constitutive relations and was incorporated in the plastic damage model using the steps specified in a recent study [25]. The uniaxial stress-strain relation from Carreira's model is given below in equation (1).

$$
\frac{f_{c}}{f_{c m}}=\frac{\beta\left(\frac{\epsilon}{\epsilon_{c m}}\right)}{\beta-1+\left(\frac{\epsilon}{\epsilon_{c m}}\right)^{\beta}}
$$

Where $\beta$ the material parameter depending on the shape of stress-strain diagram. The above equation is valid only for values of $\beta$ greater than 1 and strain values less than the ultimate strain, $\epsilon_{\mathrm{u}}$.

$$
\beta=\frac{1}{1-\frac{f_{c m}}{\epsilon_{c m} E_{i t}}}
$$

As proposed by Lubliner [26], the compressive damage variable can be calculated from equation (3):

$$
\begin{aligned}
d_{c}= & 1-\frac{1}{2+a_{c}}\left[2\left(1+a_{c}\right) \exp \left(-b_{c} \varepsilon_{c}^{i n}\right)-\right. \\
& \left.a_{c} \exp \left(-2 b_{c} \varepsilon_{c}^{i n}\right)\right]
\end{aligned}
$$

Where $a_{\mathrm{c}}$ and $b_{\mathrm{c}}$ are dimensionless coefficients, given by equation (4) and equation (5).

$$
\begin{aligned}
& a_{c}=2\left(\frac{f_{c m}}{f_{c 0}}\right)-1+2 \sqrt{\left(\frac{f_{c m}}{f_{c 0}}\right)^{2}-\left(\frac{f_{c m}}{f_{c 0}}\right)} \\
& b_{c}=\frac{f_{c 0} l_{e q}}{G_{c h}}\left(1+\frac{a_{c}}{2}\right)
\end{aligned}
$$

Table 1 Mechanical properties of concrete from material testing.

\begin{tabular}{cccc}
\hline $\begin{array}{c}\text { Density } \\
(\text { Tonne/mm }\end{array}$ & $\begin{array}{c}\mathbf{f}_{\mathbf{c m}} \\
(\mathbf{M P a})\end{array}$ & $\begin{array}{c}\mathbf{f}_{\mathrm{ct}} \\
\mathbf{( M P a )}\end{array}$ & $\begin{array}{c}\mathbf{E}_{\mathbf{c m}} \\
(\mathbf{M P a})\end{array}$ \\
\hline 2.300 & 36.08 & 3.89 & 29068 \\
\hline
\end{tabular}

The estimated properties of concrete from the 28 days compressive strength are shown in Table 2. These properties, the tensile strength and the modulus of elasticity, estimated from [28] and [29] are used for finite element model of the beam.

For tensile strength, the fictitious crack model was used while using the stress-crack width relations [27]. The crack widths were transformed into the corresponding strains. Tensile stress $\left(f_{t}\right)$ based on the fictitious crack model was calculated using the crack width $w$, as in equation (6)

$f_{t}=f_{t m}\left[1+\left(C_{1} \frac{w}{w_{c}}\right)^{3}\right] e^{-C_{2} \frac{w}{w_{c}}}-\frac{w}{w_{c}}\left(1+C_{1}^{3}\right) e^{-C_{2}}$

Where, $f_{t m}$ is the tensile strength, $\mathrm{C} 1$ and $\mathrm{C} 2$ constants with values 3 and 6.93 respectively. The critical crack width, $w_{c}$ was calculated using fracture energy, $G_{F}$, as

$$
w_{c}=5.14 \times \frac{G_{F}}{f_{t m}}
$$

The tensile damage parameter $d_{t}, a_{t}$ and $b_{t}$ can be calculated from equations (8) - (10) as

$$
\begin{aligned}
d_{t}= & 1-\frac{1}{2+a_{t}}\left[2\left(1+a_{t}\right) \exp \left(-b_{t} \varepsilon_{c}^{i n}\right)-\right. \\
& \left.a_{t} \exp \left(-2 b_{t} \varepsilon_{t}^{i n}\right)\right] \\
a_{t}= & 2\left(\frac{f_{t m}}{f_{t 0}}\right)-1+2 \sqrt{\left(\frac{f_{t m}}{f_{t 0}}\right)^{2}-\left(\frac{f_{t m}}{f_{t 0}}\right)} \\
b_{t}= & \frac{f_{t 0} l_{e q}}{G_{F}}\left(1+\frac{a_{t}}{2}\right)
\end{aligned}
$$

Table 2 Mechanical properties of concrete estimated from proposed model.

\begin{tabular}{cccc}
\hline $\begin{array}{c}\text { Density } \\
\left(\text { Tonne } / \mathrm{mm}^{3}\right)\end{array}$ & $\begin{array}{c}\mathrm{f}_{\mathrm{cm}} \\
(\mathrm{MPa})\end{array}$ & $\begin{array}{c}\mathrm{f}_{\mathrm{ct}} \\
(\mathrm{MPa})\end{array}$ & $\begin{array}{c}\mathrm{E}_{\mathrm{cm}} \\
(\mathrm{MPa})\end{array}$ \\
\hline 2.300 & 36.08 & 2.77 & 24722 \\
\hline
\end{tabular}

The uniaxial behavior of concrete in compression and tension is shown in Fig. 1 and Fig. 2, along with the damage evolution parameters, respectively. 

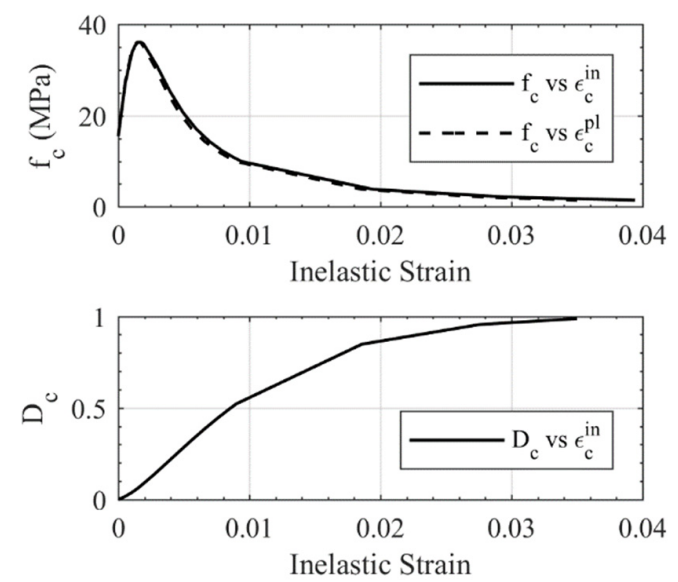

Fig. 1 Uniaxial compressive stress-strain relationship of concrete (above) with damage evolution (below).
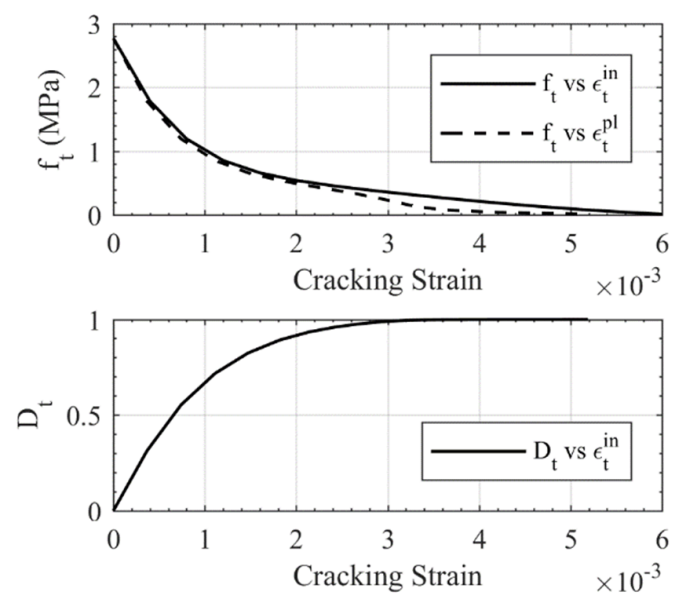

Fig. 2 Uniaxial tensile stress-strain relationship of concrete (above) with damage evolution (below)

For reinforcing steel, the tensile strength $\left(f_{y}\right)$ was used to make bilinear stress-strain curves. Deformed bars were used as bottom reinforcement and plain bars were used for top and transverse reinforcement. The properties from tensile tests are summarized in Table 3.

Table 3 Reinforcing steel mechanical properties from tensile testing.

\begin{tabular}{cccccc}
\hline Bar type & $\begin{array}{c}\text { Diamete } \\
\mathrm{r} \\
(\mathrm{mm})\end{array}$ & $\begin{array}{c}\mathrm{f}_{\mathrm{y}} \\
(\mathrm{MPa})\end{array}$ & $\begin{array}{c}\mathrm{E}_{\mathrm{s}} \\
(\mathrm{GPa} \\
)\end{array}$ & $\begin{array}{c}\nu \\
\left(\mathrm{kg} / \mathrm{m}^{3}\right. \\
)\end{array}$ \\
\hline Plain & 6 & 353.61 & 200 & 0. & 7850 \\
& & 358.83 & 200 & 0. & 7620 \\
Plain & 8 & 3 & & 3 & \\
Deforme & 16 & 559.37 & 200 & 0. & 7537 \\
d & & & & \\
\hline
\end{tabular}

\subsection{Beam details}

As this study initiated based on the experimental data from recent research [19] and the computational analysis based on the authors' work [21]. The beam specimen was kept less slender to observe the contribution of shear behavior, and also because the proposed methodology is capable of translating shear behavior along with the flexural behavior. The boundary conditions were chosen as a hinge (u1, u2) and a roller (u2). The longitudinal and the cross-sectional details of the beam are shown in Fig. 3.

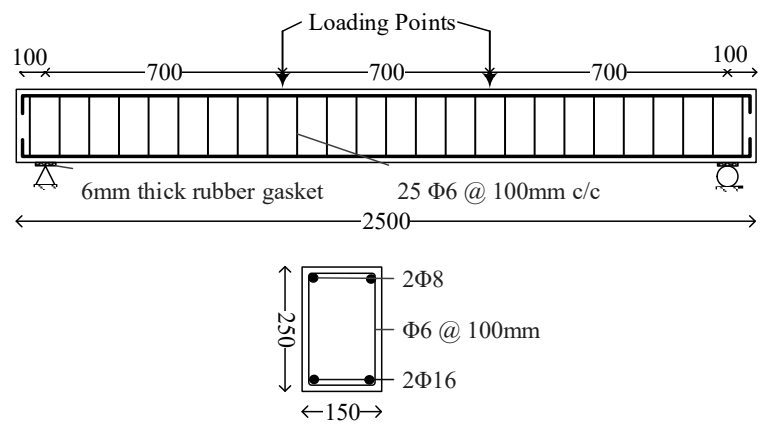

Fig. 3 Beam geometric details

\subsection{Static and dynamic procedures}

A reinforced concrete beam, as shown in Figure 3, was loaded in four-point bending. There were two types of procedures involved in the computational model of the beam using finite element software Abaqus [30], static and dynamic. In the static procedure, the loading was initially applied to the increment of $10 \%$ of the failure load first. The beam was then unloaded. For the dynamic procedure, the modal dynamic procedure was applied using a built-in command for modal analysis. The mode shapes and the resonant frequencies were recorded for comparison with the experimental results. The beam was then loaded further to the next 10 percent increment of the failure load and modal analysis was performed. This procedure continued until the estimated failure load of $110 \mathrm{kN}$.

For experimental investigation of the beam specimen, the similar procedure was followed except the dynamic analysis was carried out using an impact hammer. An accelerometer was fixed on $1150 \mathrm{~mm}$ from the support and the impact was made from impact hammer at 6 locations shown in Fig. 4. The data were recorded while carefully noting down that reasonable coherence was observed. It should be noted that the center of the beam was not available for the impact hammer due to the testing arrangement. The beam was incrementally loaded until the failure load of $\sim 110 \mathrm{kN}$ while carrying out impact hammer testing at each $11 \mathrm{kN}$ load increment.

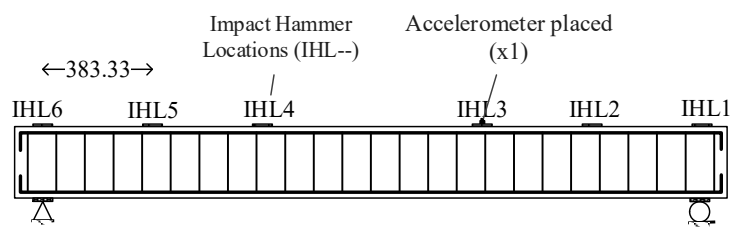

Fig. 4 Test setup for dynamic test of the beam using impact hammer 


\section{Results and Discussion}

Plasticity was combined with the continuum damage model to model reinforced concrete beam and investigate the degradation in modal frequencies with increasing damage. The results from this study can be divided into two parts: static response and dynamic response. The static response will focus on the efficacy of the model with the laboratory testing, and the dynamic response will deal with the trend of modal frequency degradation with increasing damage.

\subsection{Static response}

The static testing results comprised of load-deflection and average crack height vs deflection graphs. Fig. 5 shows the crack formation on the failed beam specimen in computation and experimentation. The flexural cracks started propagating at $2^{\text {nd }}$ cycle $(20 \%$ load of the failure load). The inclined cracks started propagating at $50 \%$ of the failure load. The crack formation and propagation matched reasonably, by computation and experimentation. Reasonable agreement was found to justify the behavior of the computational model with the actual behavior of the beam. These graphs are shown in Fig. 6 and Fig. 7.

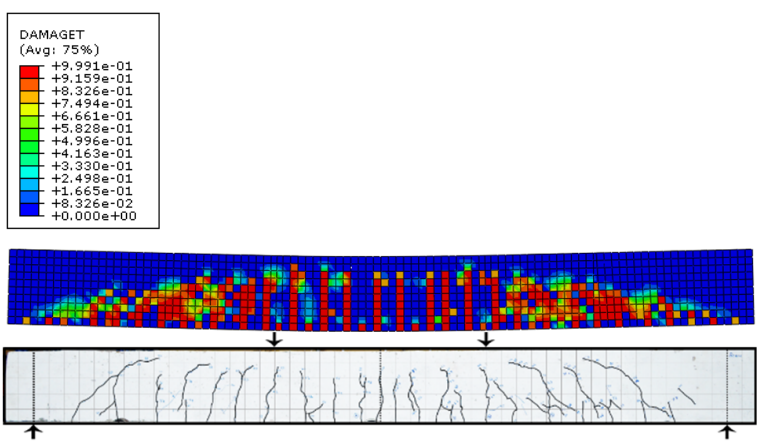

Fig. 5 Crack pattern in failed beam (above) computation and (below) experimentation.

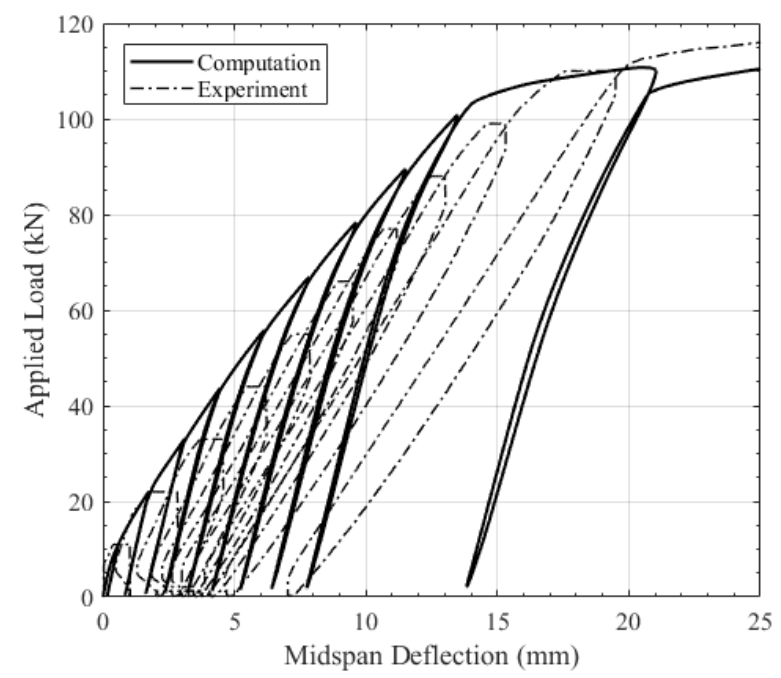

Fig. 6 Load-deflection plots comparison for experiment and computation investigation of the tested beam

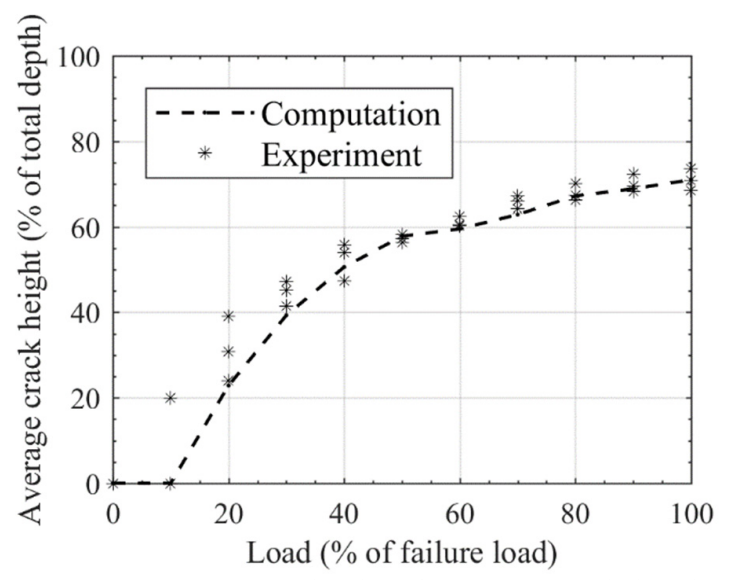

Fig. 7 Comparison of load and average crack height for computation and experiment of the tested beam

\subsection{Dynamic response}

The dynamic test results incorporate modal analysis. Fig. 8 shows the first four natural frequencies identified in the computation and the modeling. The undamaged computational modal frequencies were $61.738 \mathrm{~Hz}, 480.33$ $\mathrm{Hz}, 725.80 \mathrm{~Hz}$ and $1042.70 \mathrm{~Hz}$, whereas the modal frequencies identified from beam testing were $57.90 \mathrm{~Hz}$, $400.00 \mathrm{~Hz}, 720.00 \mathrm{~Hz}$ and $1090 \mathrm{~Hz}$, as shown in Fig. 9. An attempt was made to identify the mode shapes of the beam and reasonable mode shapes in bending were obtained for computation and the experiments. The modal frequencies and mode shapes matched, signifying the similarity of the system identified for the beam.

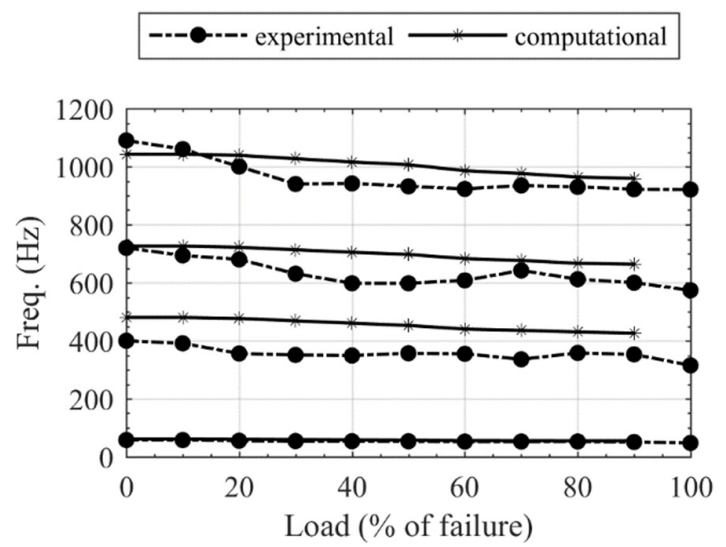

Fig. 8 First four natural frequencies trend with increasing damage as a percentage of failure load. 


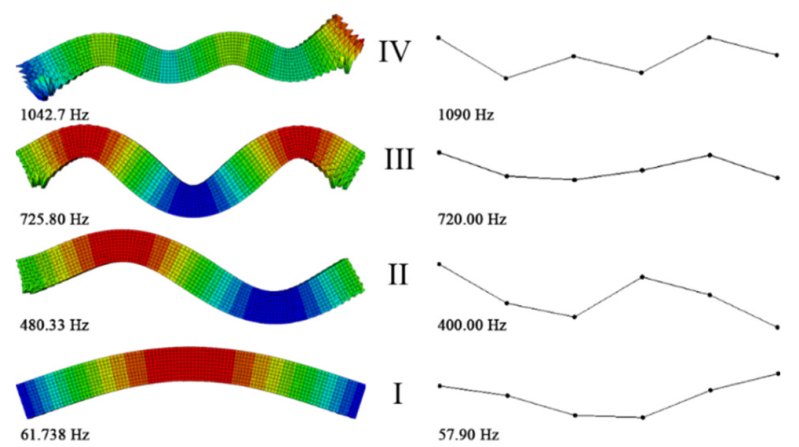

Fig. 9 Modal Analysis comparison of the reinforced concrete beam.

Now that it has been established that the model reasonably represents the mechanical behavior of the concrete and reinforcement with few simplifications in calculations, the behavior of beam needs to be investigated a bit further in detail. For this, a comparison was carried out between the damage level (represented as the percentage load of the failure load) and the average crack height (calculated by averaging the crack heights formed at different damage levels). It can be seen in Fig. 10 that there is a significant decrease in first natural frequency with crack height increasing up to the $50 \%$ of the total depth. This relates to the damage because cracks propagate the most during initial loading stages. Therefore, a graph was plotted between the damage and the first natural frequency to observe the reduction in natural frequency, as shown in Fig. 11. It can be seen that there is a drastic decrease in the natural frequencies at the initial stages of damage, which specifies that the modal analysis is more sensitive to damage at initial damage levels. Later the decrease in natural frequency with damage starts to become less. This can be attributed to the fact that the frequency reduction is more sensitive to flexural damage (vertical cracks) than when shear cracking starts (inclined cracks).

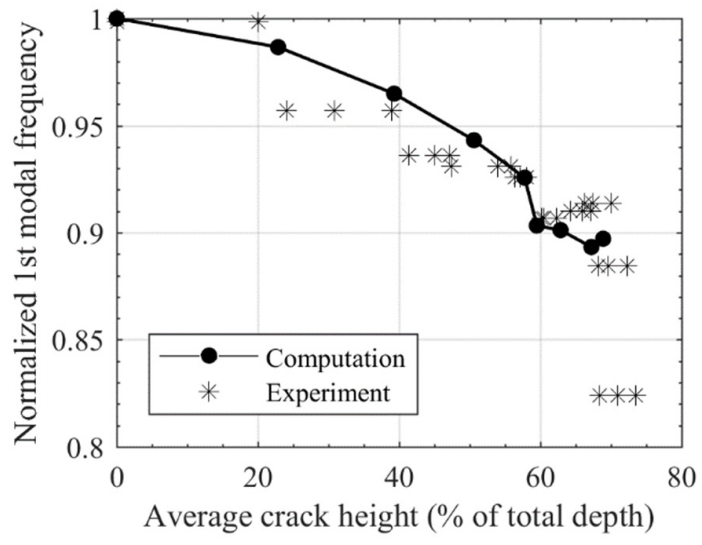

Fig. 10 Comparison of first normalized natural frequency with average crack height.

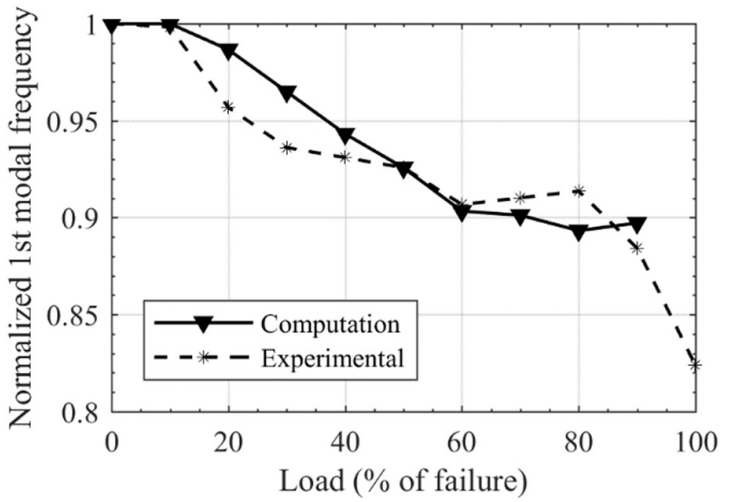

Fig. 11 Comparison of first normalized natural frequency with increasing damage (percentage of failure load)

Another point to be noted is the extent of modal frequency reduced with damage. The natural frequency only reduces to around $80 \%$ of the total value of complete beam failure. This justifies the limited efficiency of the modal methods in structural health monitoring applications, as mentioned previously [21], [31].

As the procedure of modeling concrete has already been used for non-linear modeling of reinforced concrete beams [21], the modal analysis results validate the authenticity of this model as a milestone for further developments for its applications in structural health monitoring.

\section{Conclusion}

An enhanced plastic-damage model was used to investigate its efficiency in the modal analysis for reinforced concrete beams damaged in flexure. The reinforced concrete beam was carefully modeled based on the material properties obtained from the experiment carried out. The beam was incrementally damaged using incremental static loading. After damaging the beam, dynamic analysis (model analysis for computation and impact hammer testing for the experiment) was carried out. The results show that the model reasonably represents the damage mechanics of reinforced concrete. Based on the above investigation, following conclusions can be drawn:

1. The plastic-damage model or concrete damaged plasticity model with certain modifications can be effectively used in modeling reinforced concrete structures.

2. The plastic-damage model is suitable for carrying out modal analysis of beam-type structures very accurately.

3. The modal analysis confirms the previous studies that the frequency reduction is more at initial damage levels, which means the modal frequencies are more sensitive to damage at its initial stage.

4. The total reduction in natural frequencies at complete failure is maximum 15 to $20 \%$, which validates the inadequacy of using the decline in natural frequency for damage detection in structural health monitoring application of civil engineering structures. 
With all said, the plastic damage model represents the mechanics involved in concrete damage and the response of concrete structures to dynamic analysis quite accurately. But, the versatility of plastic damage model can be extended to studying nonlinear behavior for structural health monitoring applications in reinforced concrete structures.

\section{Acknowledgements}

This research was supported by Fundamental Research Grant Scheme, Ministry of Education, Malaysia (FRGS Project No. FP004/2014B) and University Malaya Postgraduate Research Fund (PPP - Project No. PG1872014B).

\section{References}

[1] B. Lomborg, The skeptical environmentalist: measuring the real state of the world, vol. 1. Cambridge University Press Cambridge, 2003.

[2] A. Rytter, "Vibrational Based Inspection of Civil Engineering Structures," Aalborg University, 1993.

[3] H.-N. Li, T.-H. Yi, L. Ren, D.-S. Li, and L.-S. Huo, "Reviews on innovations and applications in structural health monitoring for infrastructures," Struct. Monit. Maint., vol. 1, no. 1, p. 1, Mar. 2014.

[4] C. R. Farrar and K. Worden, "An introduction to structural health monitoring.," Philos. Trans. A. Math. Phys. Eng. Sci., vol. 365, no. 1851, pp. 303-15, Feb. 2007.

[5] K. Worden, C. R. Farrar, G. Manson, and G. Park, "The fundamental axioms of structural health monitoring," Proc. R. Soc. A Math. Phys. Eng. Sci., vol. 463, no. 2082, pp. 1639-1664, Jun. 2007.

[6] H. Sohn, C. R. Farrar, F. Hemez, and J. Czarnecki, “A Review of Structural Health Monitoring Literature 1996 - 2001," pp. 1-7, 2001.

[7] S. Kim, S. Pakzad, D. Culler, J. Demmel, G. Fenves, S. Glaser, and M. Turon, "Health Monitoring of Civil Infrastructures Using Wireless Sensor Networks," 2007 6th Int. Symp. Inf. Process. Sens. Networks, pp. 254-263, Apr. 2007.

[8] F. Moreu, J. LaFave, and B. Spencer, "Structural health monitoring of railroad bridges-Research needs and preliminary results," in Structures Congress 2012, 2012, pp. 2141-2152.

[9] E. P. Carden, "Vibration Based Condition Monitoring: A Review," Struct. Heal. Monit., vol. 3, no. 4, pp. 355-377, Dec. 2004.

[10] C. R. Farrar, S. W. Doebling, and D. A. Nix, "Vibration--based structural damage identification," Philos. Trans. R. Soc. London. Ser. A Math. Phys. Eng. Sci., vol. 359, no. 1778, pp. 131-149, 2001.

[11]F. Magalhães, A. Cunha, and E. Caetano, "Vibration based structural health monitoring of an arch bridge: From automated OMA to damage detection," Mech. Syst. Signal Process., vol. 28, pp. 212-228, Apr. 2012.

[12] S. W. Doebling, C. R. Farrar, M. B. Prime, and others,
"A summary review of vibration-based damage identification methods," Shock Vib. Dig., vol. 30, no. 2, pp. 91-105, 1998.

[13] M. M. Abdel Wahab, "Effect of modal curvatures on damage detection using model updating," Mech. Syst. Signal Process., vol. 15, no. 2, pp. 439-445, Mar. 2001.

[14] M. M. Abdel Wahab, G. De Roeck, and B. Peeters, "Parameterization of Damage in Reinforced Concrete Structures Using Model Updating," J. Sound Vib., vol. 228, no. 4, pp. 717-730, Dec. 1999.

[15] M. M. Abdel Wahab and G. De Roeck, "Damage detection in bridges using modal curvatures: Application to a real damage scenario," J. Sound Vib., vol. 226, no. 2, pp. 217-235, Sep. 1999.

[16] G. D. R. M. Abdel Wahab, J. Maeck, "Numerical Simulation of Damage Scenarios of Bridge Z24," in Society for Experimental Mechanics, Inc, 17 the International Modal Analysis Conference., 1999, vol. 2, pp. 1276--1282.

[17] S. A. Neild, "Using non-linear vibration techniques to detect damage in concrete bridges," University of Oxford, 2001.

[18]B. J. Eccles, J. S. Owen, B. S. Choo, and M. Woodings, "Non-linear vibrations of cracked reinforced concrete beams," Balkema Publ. Struct. Dyn. EURODYN'99, vol. 1, pp. 357-364, 1999.

[19] W. I. Hamad, J. S. Owen, and M. F. M. Hussein, "Modelling the degradation of vibration characteristics of reinforced concrete beams due to flexural damage," Struct. Control Heal. Monit., vol. 22, no. 6, pp. 939-967, Jun. 2015.

[20] W. I. Hamad, J. S. Owen, and M. F. M. Hussein, "An efficient approach of modelling the flexural cracking behaviour of un-notched plain concrete prisms subject to monotonic and cyclic loading," Eng. Struct., vol. 51, pp. 36-50, Jun. 2013.

[21] M. U. Hanif, Z. Ibrahim, M. Jameel, K. Ghaedi, and M. Aslam, "A new approach to estimate damage in concrete beams using non-linearity," Constr. Build. Mater., vol. 124, no. C, pp. 1081-1089, 2016.

[22] L. M. Kachanov, "On the creep fracture time," Izv Akad, Nauk USSR Otd Tech, vol. 8, pp. 26-31, 1958.

[23]D. J. Carreira and K.-H. Chu, "Stress-Strain Relationship for Plain Concrete in Compression," $J$. Proc., vol. 82, no. 6, pp. 797-804, Nov. 1985.

[24]A. Hillerborg, M. Modéer, and P.-E. Petersson, "Analysis of crack formation and crack growth in concrete by means of fracture mechanics and finite elements," Cem. Concr. Res., vol. 6, no. 6, pp. 773 781, Nov. 1976.

[25]B. Alfarah, F. López-Almansa, and S. Oller, "New methodology for calculating damage variables evolution in Plastic Damage Model for RC structures," Eng. Struct., vol. 132, pp. 70-86, 2017.

[26] J. Lubliner, J. Oliver, S. Oller, and E. Oñate, "A plastic-damage model for concrete," Int. J. Solids Struct., vol. 25, no. 3, pp. 299-326, 1989.

[27] D. A. Hordijk, "Tensile and tensile fatigue behaviour of concrete; experiments, modelling and analyses," 
Heron, vol. 37, no. 1, 1992.

[28]EN1992-1-1, Eurocode 2: Design of concrete structures-Part 1-1: General rules and rules for buildings. Brussels, 2004, 2004.

[29]C. CEB-FIP, "Model Code 1990," Com. EuroInternational Du Beton, Paris, pp. 87-109, 1991.

[30]ABAQUS Documentation, "ABAQUS Analysis User's Manual," 2010.

[31] W. I. Hamad, J. S. Owen, and M. F. M. Hussein, "Modelling the nonlinear behaviour of a cracked reinforced concrete beam," in Procedings of the International Conference "Computing in Civil and Building Engineering, 2010, vol. 30. 